\title{
Boreal summer continental monsoon rainfall and hydroclimate anomalies associated with the Asian-Pacific Oscillation
}

\author{
Ping Zhao $\cdot$ Bin Wang $\cdot$ Xiuji Zhou
}

Received: 31 October 2011/Accepted: 19 March 2012/Published online: 16 May 2012

(C) The Author(s) 2012. This article is published with open access at Springerlink.com

\begin{abstract}
With the twentieth century analysis data (1901-2002) for atmospheric circulation, precipitation, Palmer drought severity index, and sea surface temperature (SST), we show that the Asian-Pacific Oscillation (APO) during boreal summer is a major mode of the earth climate variation linking to global atmospheric circulation and hydroclimate anomalies, especially the Northern Hemisphere (NH) summer land monsoon. Associated with a positive APO phase are the warm troposphere over the Eurasian land and the relatively cool troposphere over the North Pacific, the North Atlantic, and the Indian Ocean. Such an amplified land-ocean thermal contrast between the Eurasian land and its adjacent oceans signifies a stronger than normal $\mathrm{NH}$ summer monsoon, with the strengthened southerly or southwesterly monsoon prevailing over tropical Africa, South Asia, and East Asia. A positive APO implies an enhanced summer monsoon rainfall over all major NH land monsoon regions: West Africa, South Asia, East Asia, and Mexico. Thus, APO is a sensible measure of
\end{abstract}

This paper is a contribution to the special issue on Global Monsoon Climate, a product of the Global Monsoon Working Group of the Past Global Changes (PAGES) project, coordinated by Pinxian Wang, Bin Wang, and Thorsten Kiefer.

\section{P. Zhao}

National Meteorological Information Center,

Beijing 100081, China

B. Wang $(\bowtie)$

International Pacific Research Center, School of Ocean and

Earth Science and Technology, University of Hawaii at Manoa,

Honolulu, HI, USA

e-mail: wangbin@hawaii.edu

X. Zhou

Chinese Academy of Meteorological Sciences,

Beijing 100081, China the NH land monsoon rainfall intensity. Meanwhile, reduced precipitation appears over the arid and semiarid regions of northern Africa, the Middle East, and West Asia, manifesting the monsoon-desert coupling. On the other hand, surrounded by the cool troposphere over the North Pacific and North Atlantic, the extratropical North America has weakened low-level continental low and upper-level ridge, hence a deficient summer rainfall. Corresponding to a high APO index, the African and South Asian monsoon regions are wet and cool, the East Asian monsoon region is wet and hot, and the extratropical North America is dry and hot. Wet and dry climates correspond to wet and dry soil conditions, respectively. The APO is also associated with significant variations of SST in the entire Pacific and the extratropical North Atlantic during boreal summer, which resembles the Interdecadal Pacific Oscillation in SST. Of note is that the Pacific SST anomalies are not present throughout the year, rather, mainly occur in late spring, peak at late summer, and are nearly absent during boreal winter. The season-dependent APO-SST relationship and the origin of the APO remain elusive.

\section{Introduction}

In the past five decades, the global land monsoon precipitation showed an overall weakening (Wang and Ding 2006), which is mainly associated with the decreases of the North African and South Asian precipitation (Zhou et al. 2008a). Since 1980, however, the global land monsoon precipitation did not show a significant trend. These results suggest that the variation over the last 50 years may be a part of longer time scale variations. This motivates our present study, which will examine a century-long change in global land rainfall and the twentieth century reanalysis 
circulations. Because a recent study of Wang et al. (2012) has shown that the mechanisms responsible for the northern and southern hemisphere summer monsoons are not same, this study will focus on the northern hemisphere summer monsoon.

Many studies have shown that the variations in the Northern Hemispheric monsoon precipitation are associated with global ocean-atmosphere-land interactions. For example, the variability of the monsoon precipitation over North Africa, Asia, and North America are strongly affected by the Pacific and Indian Ocean sea surface temperatures (SSTs) (Ropelewski and Halpert 1987; Webster and Yang 1992; Yang and Lau 1998; Wang et al. 2000, 2001; Fasullo and Webster 2002; McCabe et al. 2004; Zhou et al. 2008b; Hu and Huang 2009). While the summer precipitation over Asia and Africa is related to the El NiñoSouthern Oscillation (ENSO) (Ropelewski and Halpert 1987), the summer monsoon precipitation over southern and northern China is linked to both ENSO and the Pacific decadal oscillation (PDO) (Zhu and Yang 2003; Chan and Zhou 2005). Moreover, PDO is also linked to summer Indian monsoon precipitation (Krishnan and Sugi 2003) and affects the relationship between ENSO and northeast Asian summer monsoon (Yoon and Yeh 2010).

Recently, Zhao et al. (2007, 2010a) found that the variability of a summertime large-scale teleconnection pattern over the extratropical Northern Hemisphere $(\mathrm{NH})$, with anomalous centers over the Asian-North Pacific sector, referred to as the Asian-Pacific Oscillation (APO), is highly correlated to the major atmospheric circulation systems over the $\mathrm{NH}$ and to the tropical-extratropical North Pacific SST. The similar atmospheric teleconnection and its links to SST were also investigated by Zhou and Zhang (2009). On the interdecadal scale, the APO is associated with precipitation over Asia and extratropical North America (Zhao et al. 2011a). Then, how are the NH summer land monsoon (NHSM) and tropospheric atmospheric circulation and hydroclimate (including surface air temperature, precipitation, and drought) related to the APO during boreal summer? With this question in mind, we conduct this study to systematically examine the varying features of summer APO-related atmospheric circulation, temperature, rainfall, drought, and SST as well as the NHSM using the 1901-2002 datasets.

The rest of this paper is organized as follows. We describe the features of datasets used in this study in Sect. 2 and then examine the variability of the boreal summer APO index in Sect. 3 and the dynamic structure of the APO in Sect. 4. The NHSM and global hydroclimate anomalies associated with the APO are analyzed in Sects. 5 and 6, respectively. The variations of lower oceanic boundary forcing associated with the APO are examined in Sect. 7. Finally, a summary and a discussion are provided in Sect. 8.

\section{Data}

This study utilizes the monthly mean data from the twentieth century reanalysis V2 products with a horizontal resolution of $2^{\circ} \times 2^{\circ}$ latitude and longitude for 1871-2008 (Compo et al. 2006, 2011), the National Centers for Environmental Prediction-National Center for Atmospheric Research (NCEP/NCAR) reanalysis with a horizontal resolution of $2.5^{\circ} \times 2.5^{\circ}$ during 1948-2002 (Kalnay et al. 1996), and the European Centre for Medium-range Weather Forecast 40-year reanalysis dataset with a horizontal resolution of $2.5^{\circ} \times 2.5^{\circ}$ during 1958-2001 (ERA40) (Uppala et al. 2005). Moreover, we also use the monthly mean surface air temperature and total precipitation over global land from the Climatic Research Unit $(\mathrm{CRU})$ analysis with a horizontal resolution of $0.5^{\circ} \times 0.5^{\circ}$ during 1901-2002 (New et al. 2000), the monthly Palmer drought severity index (PDSI) with a horizontal resolution of $2.5^{\circ} \times 2.5^{\circ}$ during $1870-2005$ (Dai et al. 2004), and the monthly mean SST from the Hadley Centre Sea Ice and Sea Surface Temperature (HadISST) with a horizontal resolution of $1^{\circ} \times 1^{\circ}$ during 1870-2002 (Rayner et al. 2003).

An Empirical Orthogonal Function (EOF) analysis with area weighting is conducted to detect a teleconnection pattern. Correlation and regression analyses are applied to examine the relationships between different variables. The statistical significance of correlation coefficients, regression analyses, and non-zero trends is assessed at the $95 \%$ confidence level (Student $t$ test) unless otherwise stated. Following Zhao et al. (2011a, b), in the present study, a mean of May, June, July, August, and September (MJJAS) is used to represent boreal summer.

\section{Definition and variability of the APO index}

The planetary scale climate departures are better identified at the upper troposphere than at the lower troposphere. The zonally asymmetric thermal structure can be depicted by the zonal departure of temperature $\left(T^{\prime}\right)$, which is obtained by removing the background zonal mean (symmetric) temperature $(\bar{T})$ from the total temperature field $(T)$.

The APO index may be defined by the leading principal component of the NH upper troposphere (300-200-hPa) zonal departure of the temperature field (Zhao et al. 2010a, 2011a). Using the monthly data of the twentieth century reanalysis V2 products during 1871-2008, the first EOF mode (EOF1) of the MJJAS NH 300-200-hPa temperature departure $\left(T^{\prime}\right)$ is computed. Figure 1a shows that the EOF1 exhibits an out-of-phase variation (a zonal wavenumber-1 feature) over the extratropical $\mathrm{NH}$, with positive values 

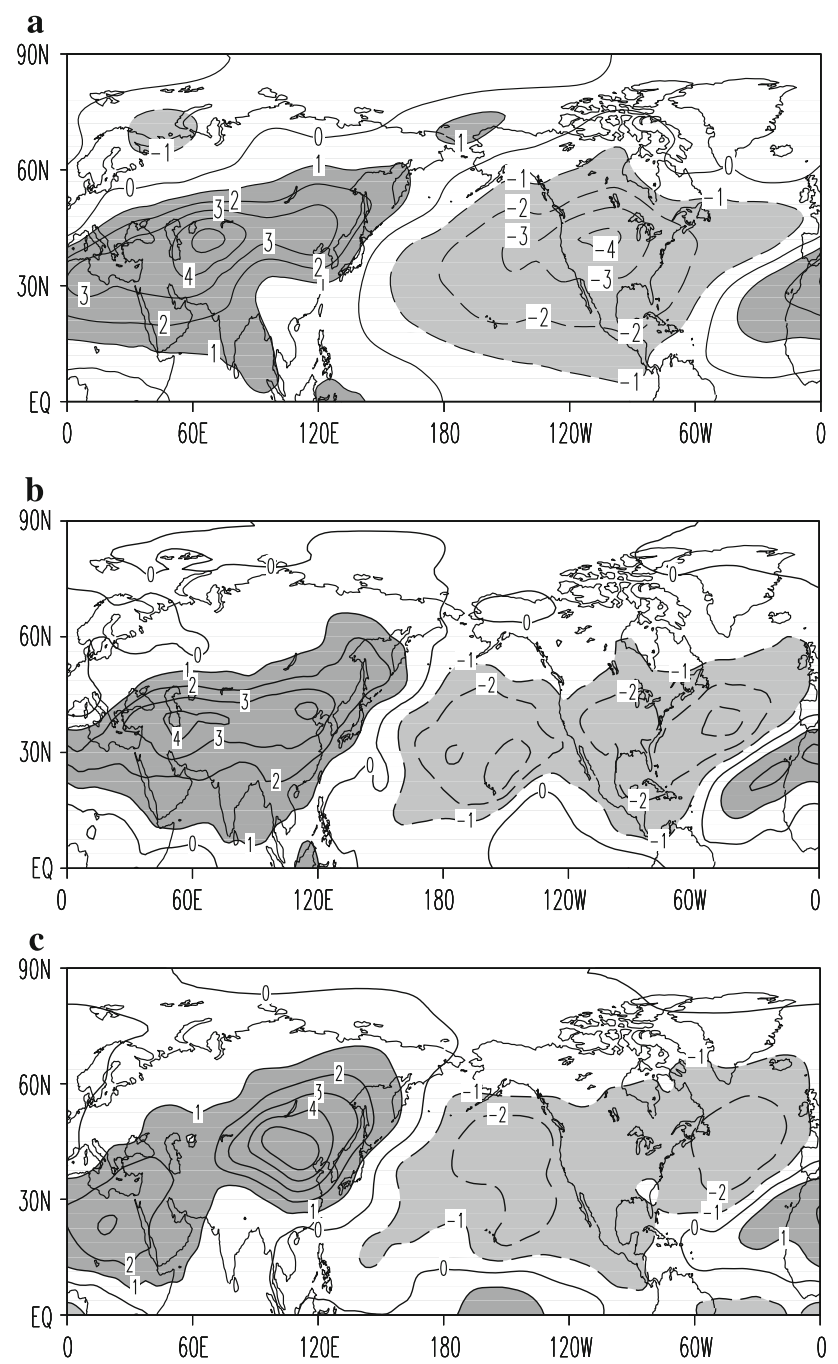

Fig. 1 a EOF1 $(\times 0.1)$ of MJJAS 300-200-hPa $T^{\prime}$ for the twentieth century reanalysis (Zhao et al. 2011a, b); b same as a but for the ERA-40 reanalysis during 1958-2001; and c same as (a) but for the NCEP reanalysis during 1948-2002

mainly over Eurasia and northern subtropical Africa and negative values mainly over the extratropics of the North Pacific, North America, and the North Atlantic. When the principal component of the EOF1 is higher (lower), the tropospheric temperature is warming over the Eurasiannorthern African land and cooling over the North Pacific, North America, and the North Atlantic (figure not shown).

The principal component of the EOF1, which indicates the variability of the APO pattern, is defined as the APO index. Figure 2 shows the standardized summer APO index. For the entire study period of 1901-2002, the summer APO index did not show a significant trend. Positive anomalies of the APO index mainly occurred from 1920 to 1946 and from 1959 to 1975, while negative anomalies mainly appeared in other periods. This multidecadal variation indicates a general increase before 1946 and an overall decrease after 1960, that is, a warming (cooling) troposphere occurs over Eurasia (the North Pacific, North America, and the North Atlantic) during the $1900 \mathrm{~s}$ to the $1940 \mathrm{~s}$ and an opposite varying trend occurs during the subsequent decades. This result also suggests that the tropospheric cooling over East Asia noted by $\mathrm{Yu}$ et al. (2004) usually accompanies the tropospheric warming over the oceans during the past five decades. Moreover, the APO index also shows interannual variability. A power spectrum analysis of the summer APO index during 1901-2002 demonstrates predominant peaks at 3-4 years and 50 years (significant at the $95 \%$ level). This shorter oscillation period is also observed in the APO index from the 1958-2001 ERA-40 reanalysis (Zhao et al. 2007).

On the climatological map of MJJAS upper-tropospheric (300-200 hPa) mean temperature departure $\left(T^{\prime}\right)$ (figure not shown), a salient feature is the contrast between the warm eastern Hemisphere and the cold western Hemisphere in the subtropics and midlatitudes, which indicates a striking east-west temperature contrast between Eurasia and the North Pacific to the North Atlantic. Comparing Fig. 1a with the climatological mean of $T$, it is seen that corresponding to a higher (lower) principal component of the EOF1, an extra positive (negative) tropospheric $T^{\prime}$ anomaly over Eurasia and an extra negative (positive) tropospheric $T^{\prime}$ anomaly over the North Pacific to the North Atlantic are added to the climatological mean of $T^{\prime}$, enhancing (weakening) the east-west contrast between the warm center over Eurasia and the cold centers over the oceans. We calculate the correlation of the principal component of the EOF1 with the 300-200-hPa $T$ contrast between Asia and the North Pacific, in which Asia and North Pacific are defined as the regions $60^{\circ} \mathrm{E}-120^{\circ} \mathrm{E} / 15^{\circ} \mathrm{N}-50^{\circ} \mathrm{N}$ and $180^{\circ} \mathrm{W}-120^{\circ} \mathrm{W} / 15^{\circ} \mathrm{N}-50^{\circ} \mathrm{N}$, respectively. The result shows a significant (at the $99.9 \%$ confidence level) positive correlation of 0.91 for the period 1901-2002. Thus, the variability of APO reflects an enhanced or weakened feature of the climatological mean tropospheric temperature, i.e., the east-west contrast between the Eurasian land and the North Pacific and the North Atlantic.

Moreover, on the regressed tropospheric $T^{\prime}$ map against the principal component of the EOF1 (figure not shown), corresponding to a warm (cool) troposphere over Eurasia, the troposphere over the tropical Indian Ocean is relatively cool (warm). The land-sea meridional thermal contrast between the Asian continent and the Indian Ocean may be indicated by the difference of $500-200-\mathrm{hPa}$ thickness between the Tibetan region $\left(20^{\circ} \mathrm{N}-40^{\circ} \mathrm{N}, 60^{\circ} \mathrm{E}-100^{\circ} \mathrm{E}\right)$ and the tropical Indian Ocean $\left(10^{\circ} \mathrm{S}-10^{\circ} \mathrm{N}, 60^{\circ} \mathrm{E}-100^{\circ} \mathrm{E}\right)(\mathrm{Sun}$ et al. 2010). Their South Asian thermal contrast index, called the Sun index in this study, is calculated using the twentieth century reanalysis. Correlation analysis shows 
Fig. 2 The standardized MJJAS APO indices defined by the leading principal component and derived from the twentieth century reanalysis (black) during 1901-2002, the NCEP/ NCAR reanalysis (green) during 1948-2002, and the ERA-40 reanalysis (purple) during 1958-2001

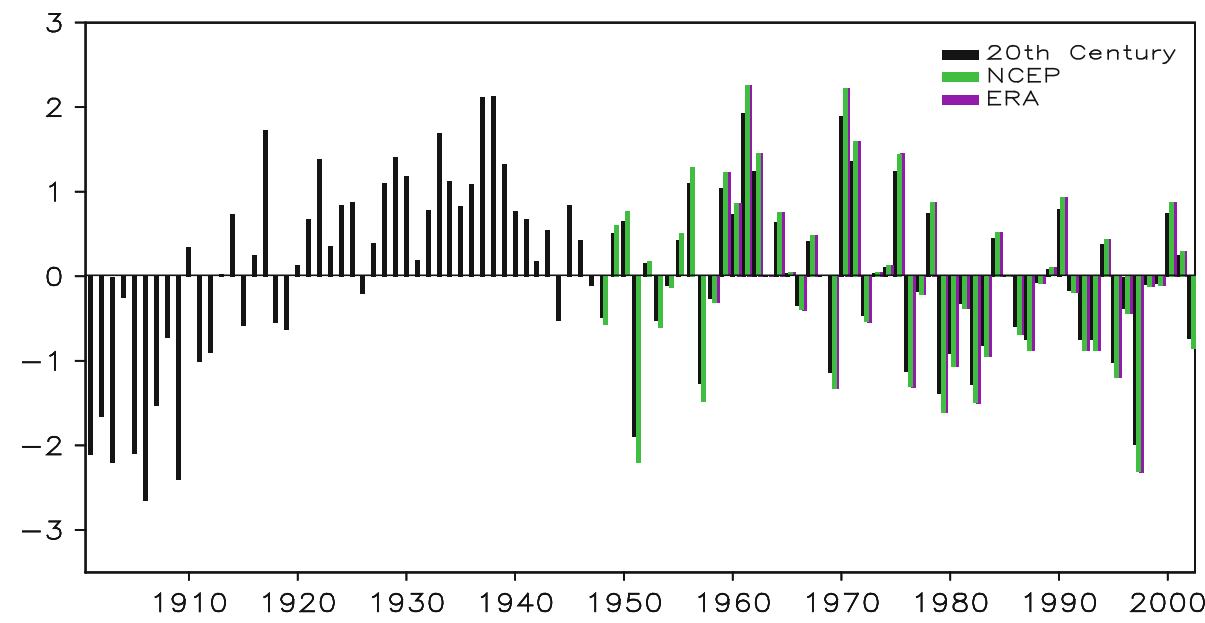

that the Sun index is highly correlated with the APO index, with a correlation coefficient of 0.76 during 1901-2002. Such a high correlation suggests the consistency between the APO and the South Asian meridional thermal contrast, that is, associated with a positive (negative) APO phase are the warm (cool) troposphere over the Tibetan region and the relatively cool (warm) troposphere over the tropical Indian Ocean.

We further perform an EOF analysis on MJJAS 300-200-hPa $T^{\prime}$ using the 1958-2001 ERA-40 and 1948-2002 NCEP reanalysis datasets. The results show that the APO pattern is also detected in these reanalysis datasets (Fig. 1b, c). Compared to the ERA-40 reanalysis and the twentieth century reanalysis (Fig. 1a, b), however, positive central values in the NCEP reanalysis over East Asia are much larger than negative central values over the North Pacific and Atlantic in magnitude (Fig. 1c). Combined with the principal component of the EOF1 in the NCEP reanalysis (Fig. 2), this enhanced center over East Asia indicates a pronouncedly decreasing trend of tropospheric temperature during the past decades ( $\mathrm{Yu}$ et al. 2004) and is possibly overestimated in the NCEP reanalysis because of an operational change in the bias correction tables since 1992 (Liu et al. 2012b).

The summer APO indices derived from the ERA-40 and NCEP reanalysis datasets are shown in Fig. 2. Obviously, the APO index derived from the twentieth century reanalysis agrees very well with those derived from the ERA-40 (NCEP) reanalysis during 1958-2001 (1948-2002) with a correlation coefficient of $0.84(0.58)$, both significant at the $99.9 \%$ confidence level. After removing their linear trends during 1958-2001 (1948-2002), the correlation coefficient is 0.85 (0.72). This result shows the good consistency between the twentieth century reanalysis and the ERA-40 or NCEP reanalysis, suggesting the reliability of the APO index obtained from the twentieth century reanalysis. In the following analysis, we use the APO index for the period
1901-2002 to analyze its relationships with atmospheric circulation, NHSM, hydroclimate, and SST over the past century.

\section{Dynamic structure of the APO}

The large-scale atmospheric circulation anomalies associated with the APO (Fig. 3) indicate that the Asian-African monsoon circulation shows a prominent anomalous condition. For example, the anomalous cyclonic system at $850 \mathrm{hPa}$ occurs over the Asian-African monsoon region, with the anomalous centers in northern Africa, South Asia, and East Asia, indicating the strengthened continental low (monsoon trough) over these regions (Fig. 3a). The strengthened cross-equatorial southerly or southwesterly winds from the South Indian Ocean flow into the AfricanSouth Asian monsoon region and then into the East Asian monsoon region. The strengthened southwesterly winds not only increase the transportation of water vapor toward these monsoon regions but also strengthen moisture convergence in the monsoon troughs. In the upper troposphere (Fig. 3b), an anomalous anticyclone covers the mid-low latitudes of the Asian-African monsoon region, indicating the strengthened South Asian high that is centered near the Tibetan Plateau, and there are easterly or northeasterly wind anomalies to the south of the anomalous anticyclonic center, which enhances the southward cross-equatorial flow and upper-level divergence over the Asian-African monsoon region.

At the same time, low-level anomalous anticyclonic system over the North Atlantic stretches westwards into the extratropical North America, indicating a weakened low pressure system over extratropical North America; and upper-level anomalous cyclonic system over the North Pacific extends eastwards into the western part of extratropical North America, indicating a weakened Mexican 

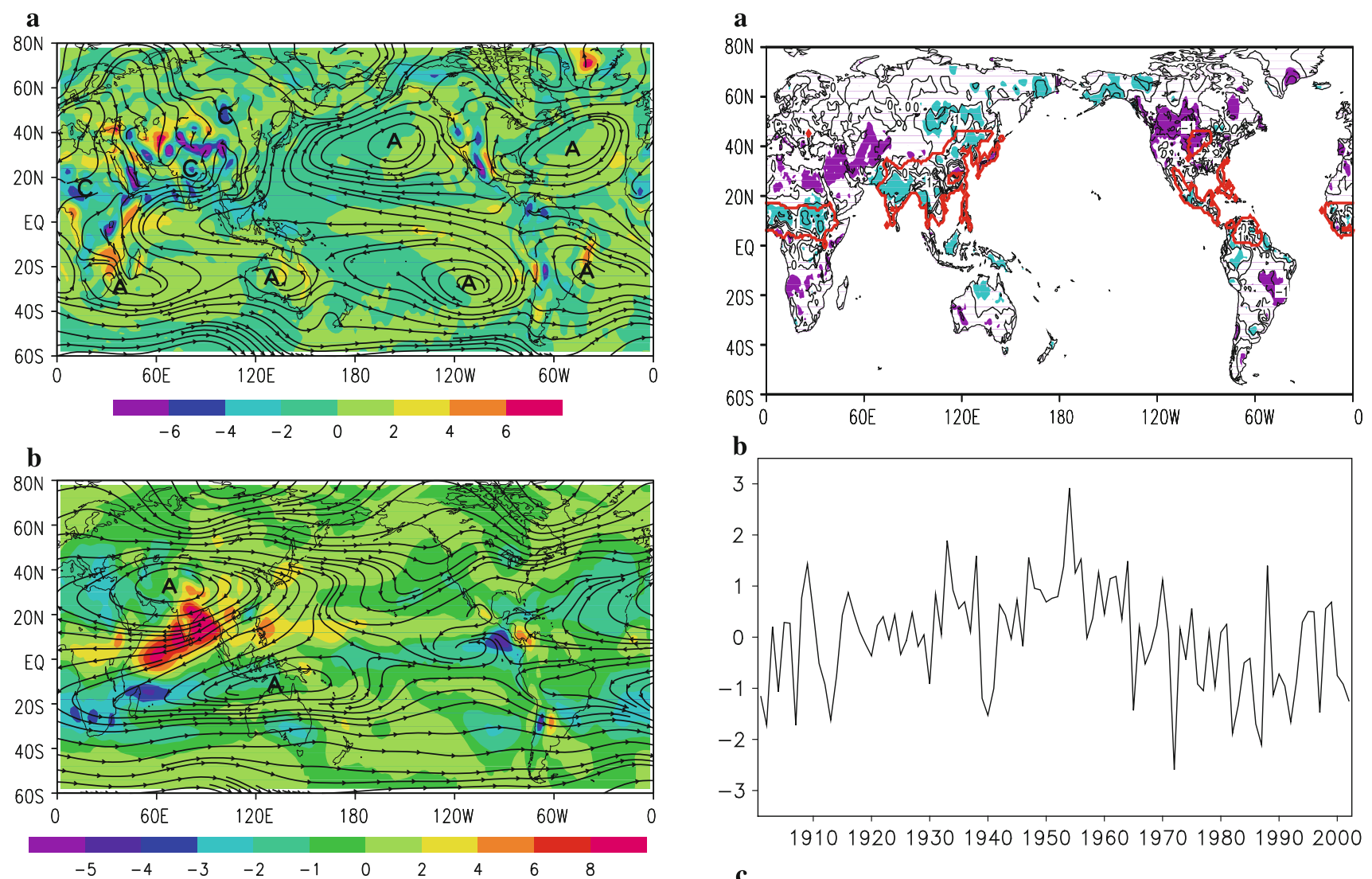

Fig. 3 Circulation structure associated the APO. a Regressed MJJAS $850-\mathrm{hPa}$ flow field and its convergence/divergence $\left(\times 10^{-7} / \mathrm{s}\right.$; shaded areas) with reference to the APO index during 1901-2002; and b same as (a) but for $150 \mathrm{hPa} . A$ and $C$ indicate positions of anomalous anticyclone and cyclone centers, respectively

ridge (Fig. 3). Thus over extratropical North America, a positive APO corresponds to weakened low-level cyclonic system and upper-level anticyclonic system, and weakened low-level convergence and upper-level divergence. Meanwhile, smaller-scale strengthened low-level convergence and upper-level divergence occur over the Mexican tropical monsoon region.

Over the winter Southern Hemisphere (SH) (Fig. 3), corresponding to a positive APO, low-level anomalous anticyclonic systems occur over the subtropics, indicating the strengthened subtropical high. In the upper troposphere, an anomalous anticyclonic system appears over the tropical South Indian Ocean and Australia and anomalous cyclonic circulation appears over the subtropical South Pacific.

\section{Northern Hemisphere summer monsoons associated with the APO}

As shown in Fig. 3, a positive APO phase indicates an enhanced Asian monsoon circulation system, which is characterized by the strengthened upper-level South Asian

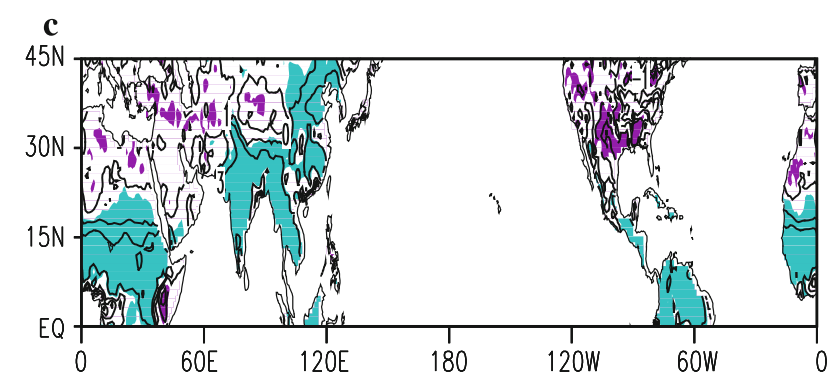

Fig. 4 a Regressed MJJAS precipitation $(\times 10 \mathrm{~mm})$ with reference to the APO index during 1901-2002 (shaded areas are significant at the $90 \%$ confidence and red lines outline the monsoon precipitation domain according to the definition of Wang and Ding (2006)); $\mathbf{b}$ the standardized NHSM index during 1901-2002; and $\mathbf{c}$ regressed MJJAS precipitation $(\times 10 \mathrm{~mm})$ with respect to the NHSM index during 1901-2002

High and associated easterly jet, southward cross-equatorial flow and divergence, and by the enhanced low-level monsoon trough and associated southwest monsoon, northward cross-equatorial flow and monsoon trough convergence. As a consequence, the precipitation over the South Asian and East Asian monsoon regions are generally abundant except that small-scale less precipitation occurs over eastern China near $30^{\circ} \mathrm{N}$ (Fig. 4a). The APO-precipitation relationship over the East Asian monsoon region is basically consistent with that obtained from the 1958-2001 ERA-40 reanalysis and the gauge precipitation at meteorological stations of China (Zhao et al. 2007). This 
consistency implies a stable link between the boreal summer APO and East Asian monsoon precipitation over the twentieth century and supports the reliability of the twentieth century reanalysis.

Of particular note is that the positive APO-related precipitation increase is not only found in the Asian monsoon region, but also over the West African and Mexican tropical monsoon regions (Fig. 4a), which is consistent with the strengthened low-level convergence and upper-level divergence found over West Africa and the Mexican monsoon region shown in Fig. 3. The enhanced West African monsoon rainfall is also closely associated with the strengthened upper-level easterly jet to the southwest of the South Asian High as a result of Rossby wave response. This enhanced easterly jet increases the vertical easterly shear over the Sahel region, and thus the dynamic instability-a critical process destabilizing African easterly wave that is the rain-bearing system of the West African monsoon. The enhanced rainfall over the Mexican monsoon region is pretty local, reflecting an in situ strengthening upward motion in contrast to the strong subsidence over the great plains of North America.

The above results show that a positive APO implies a synchronous enhancement in the West African, South Asian, East Asian, and Mexican monsoons. This steady relationship suggests that APO is a sensible measure of the $\mathrm{NH}$ land monsoon rainfall intensity.

To directly measure the NHSM land precipitation, we compute an NHSM index using the CRU precipitation data for the period 1901-2002 following the procedure of Wang and Ding (2006, 2008). The NHSM index is defined as the MJJAS precipitation rate averaged over the entire NHSM domain (shown in Fig. 4a) and the time series is shown in Fig. 4b. Figure $4 \mathrm{c}$ shows the regressed MJJAS precipitation with reference to the NHSM index during 1901-2002. It is seen that significant positive anomalies mainly appear over the West African, South Asian, East Asian, and Mexican monsoon regions and over the northern South America. This anomaly pattern is very similar to that associated with the positive APO (shown in Fig. 4a). The APO index and the NHSM index shows a correlation coefficient of 0.55 (significant at the $99.9 \%$ confidence level) during 1958-2002 and a correlation of 0.31 (significant at $99 \%$ confidence level) for the period 1901-2002. This consistency further demonstrates a close link between the APO and the NHSM. Comparison of the time series of the two indices (Figs. 2, 4b) indicates that both time series showed an increasing trend from 1901 to 1940 and a decreasing trend from 1960 to 2002 . The similar varying feature in the NHSM index is also revealed by Zhang and Zhou (2011). However, the large discrepancy between the APO and NHSM indices is seen during 1940-1960. We examine the correlation coefficient between these two indices on the interdecadal time scale, in which the interdecadal components of these indices come from the 9-years running means. The result shows that the correlation coefficient between the interdecadal components is 0.38 (exceeding the $90 \%$ confidence level) during 1901-2002. It is evident that the discrepancy between APO and NHSM during such a shorter period of 1940-1960 does not change the significant positive correlation on the interdecadal time scale in the entire study period. Further investigation of that period may be necessary for understanding the nonstationarity of the APO-NHSM relationship.

\section{Global hydroclimate anomalies associated with the APO}

\subsection{Surface air temperature}

Figure 5 shows the regressed CRU surface air temperature over the global land with reference to the APO index during 1901-2002. There are generally positive anomalies of surface air temperature over the high latitudes of Europe, the Far East of Russia, the central-eastern and northeastern parts of China, Japan, the Korean Peninsula, and North America between $30^{\circ} \mathrm{N}$ and $60^{\circ} \mathrm{N}$, with their central values exceeding $0.3{ }^{\circ} \mathrm{C}$. Negative anomalies of surface air temperature mainly appear over Africa, South Asia, Australia, the tropics of North America, and South America. This result indicates a close relationship between APO and surface air temperature over the global land.

\subsection{Precipitation}

In addition to the positive precipitation anomalies occurring in the NHSM regions, negative precipitation anomalies appear over the arid and semiarid regions of northern Africa, the Middle East, and West Asia (Fig. 4a). This

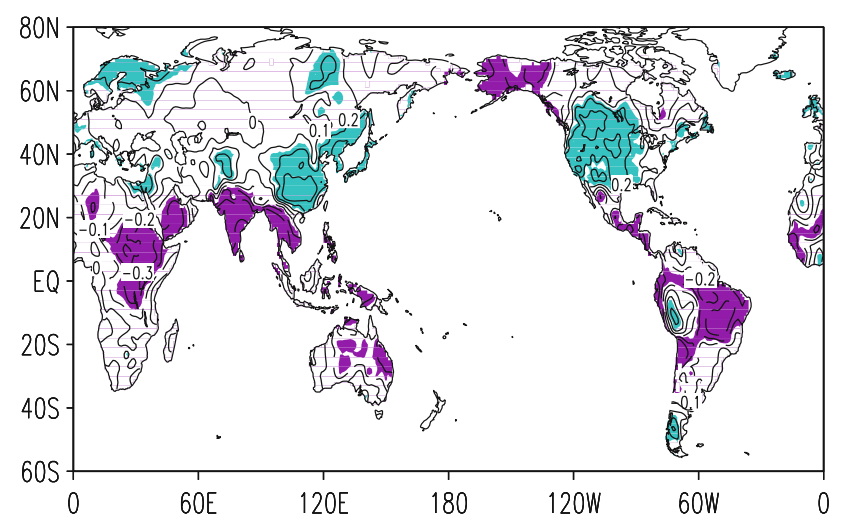

Fig. 5 Regressed MJJAS surface air temperature $\left({ }^{\circ} \mathrm{C}\right)$ with reference to the APO index during 1901-2002 (shaded areas are significant at the $90 \%$ confidence) 
manifests the monsoon-desert coupling. The intensified monsoon rainfall can reduce precipitation over the adjacent arid regions located to the west and poleward of the monsoon region. The latter results from the increased descent in the dry region through the interaction between Rossby wave and mean westerly flow (Hoskins and Rodwell 1995) and the enhanced transverse monsoon circulations driven by differential radiative heating (Webster et al. 1998). Over extratropical North America, associated with a high APO index is the local weakened upward motion (figure not shown) because of both the weakened lower-level convergence and high-level divergence. Accordingly, large-scale significant negative precipitation anomalies cover most of North America between $30^{\circ} \mathrm{N}$ and $60^{\circ} \mathrm{N}$, with the negative central value below $30 \mathrm{~mm}$ (Fig. 4a).

\subsection{Palmer drought severity index}

The occurrence of a regional drought may synthetically be affected by local temperature and precipitation. Figure 6 shows the regressed summer PDSI against the APO index during 1901-2002. Significant positive anomalies of the PDSI mainly appear over Africa, the Asian monsoon region, the Far East of Russia, the high latitudes of North America, and South America, indicating a wetter soil condition. Large-scale significant negative anomalies of the PDSI mainly occur over the mid latitudes of North America and some scattered negative anomalies appear over Europe and West Asia, corresponding to a drier soil condition. Dai et al. (2004) gave the EOF2 pattern of the global PDSI in their Fig. 6. Their pattern exhibits positive anomalies over Africa, the Asian monsoon region, Australia, the Far East of Russia, the high latitudes of North America, and the tropics of South America and negative anomalies over Europe, West Asia, and the midlatitudes of North America. Generally speaking, their EOF2 pattern is consistent with the anomalous pattern associated with the

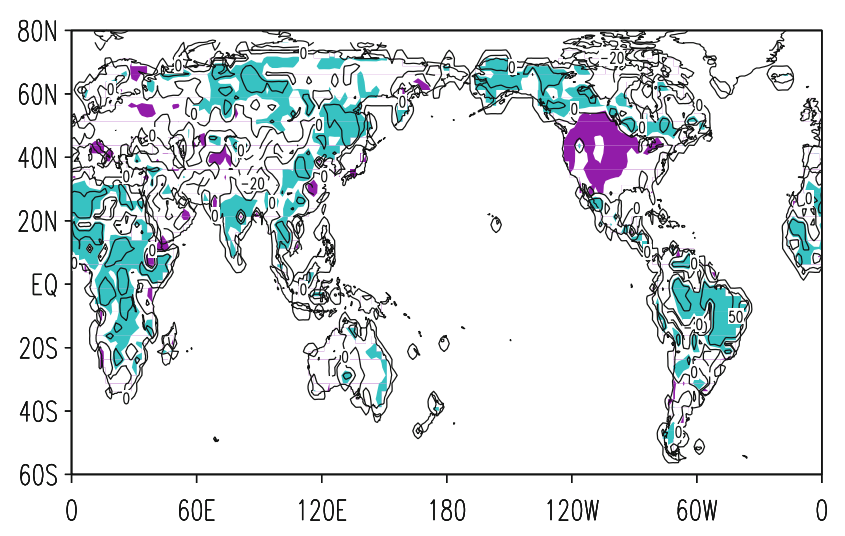

Fig. 6 Regressed MJJAS Palmer drought severity index with reference to the APO index during 1901-2002 (shaded areas are significant at the $90 \%$ confidence)
APO, which suggests that global teleconnection in the PDSI is possibly related to the APO anomaly.

Combining soil moisture (in Fig. 6) with surface air temperature (in Fig. 5) and precipitation (in Fig. 4a), we may obtain a general climate feature for different regions. For example, over the African and South Asian monsoon regions, the higher-than-normal precipitation and lowerthan-normal temperature indicate a wet-cold climate and may contribute to an increase of the local soil moisture. Over the East Asian monsoon region, more precipitation is often accompanied by higher temperature, which indicates a wet-hot climate, and precipitation may be a major factor for an increase of the local soil moisture. Such a wet-hot climate may be associated with the strengthened transport of warm and wet air masses by the southwesterly wind anomalies coming from the tropical oceans (shown in Fig. 3a) into the East Asian monsoon region. On the interdecadal time scale, however, a wet-cool or dry-hot climate is also possible ( $\mathrm{Yu}$ and Zhou 2007). Over the extratropics of North America, both less precipitation and higher temperature indicate a dry-hot climate and contribute to the local decreased soil moisture.

\section{APO and lower boundary forcing over oceans}

The previous study has noted the link of the APO with ENSO and PDO (Zhao et al. 2010a, 2011b). Here, we further examine the relationship between the APO and global SST. Figure 7a shows the regressed MJJAS mean SST against the APO index during 1901-2002. Large-scale significant positive and negative anomalies appear over the extratropical North Pacific and the tropical Pacific, respectively, with a correlation coefficient of 0.37 (significant at the $99.9 \%$ confidence level) between APO and SST over the extratropical North Pacific $\left(35^{\circ} \mathrm{N}-45^{\circ} \mathrm{N}, 160^{\circ} \mathrm{E}-\right.$ $180^{\circ} \mathrm{E}$ ) during $1901-2002$ and a correlation coefficient of 0.39 between APO and SST over the equatorial centraleastern Pacific $\left(10^{\circ} \mathrm{S}-10^{\circ} \mathrm{N}, 180^{\circ} \mathrm{W}-80^{\circ} \mathrm{W}\right)$. For the period 1958-2002, the correlation coefficients of APO with the extratropical North Pacific and the tropical Pacific SSTs are 0.55 and -0.67 in turn, consistent with those from the ERA40 and HadISST datasets (Zhao et al. 2010a). The result here demonstrates the stability of the APO-PDO or APOENSO relationship over the past century, also supporting the reliability of the twentieth century reanalysis. Meanwhile, there are large-scale positive anomalies of SST over the subtropical South Pacific, with a correlation coefficient of 0.41 between APO and SST over the subtropical South Pacific $\left(20^{\circ} \mathrm{S}-40^{\circ} \mathrm{S}, 170^{\circ} \mathrm{E}-150^{\circ} \mathrm{W}\right)$ during $1901-2002$. The correlation coefficient is 0.43 during 1958-2002. Comparing Fig. 7a with Fig. 3a, the positive SST anomalies of the extratropical South and North Pacific and North Atlantic 
corresponds to the local lower-tropospheric anomalous anticyclonic circulations; and the negative SST anomalies of the tropical central-eastern Pacific corresponds to the local lower-tropospheric anomalous easterly winds, which indicates an ocean-atmosphere coupled relationship similar to the typical feature of La Niña.

In order to compare the anomalous SST pattern (Fig. 7a) with the variability of SST itself, we perform an EOF analysis on the MJJAS SST over the globe. The result
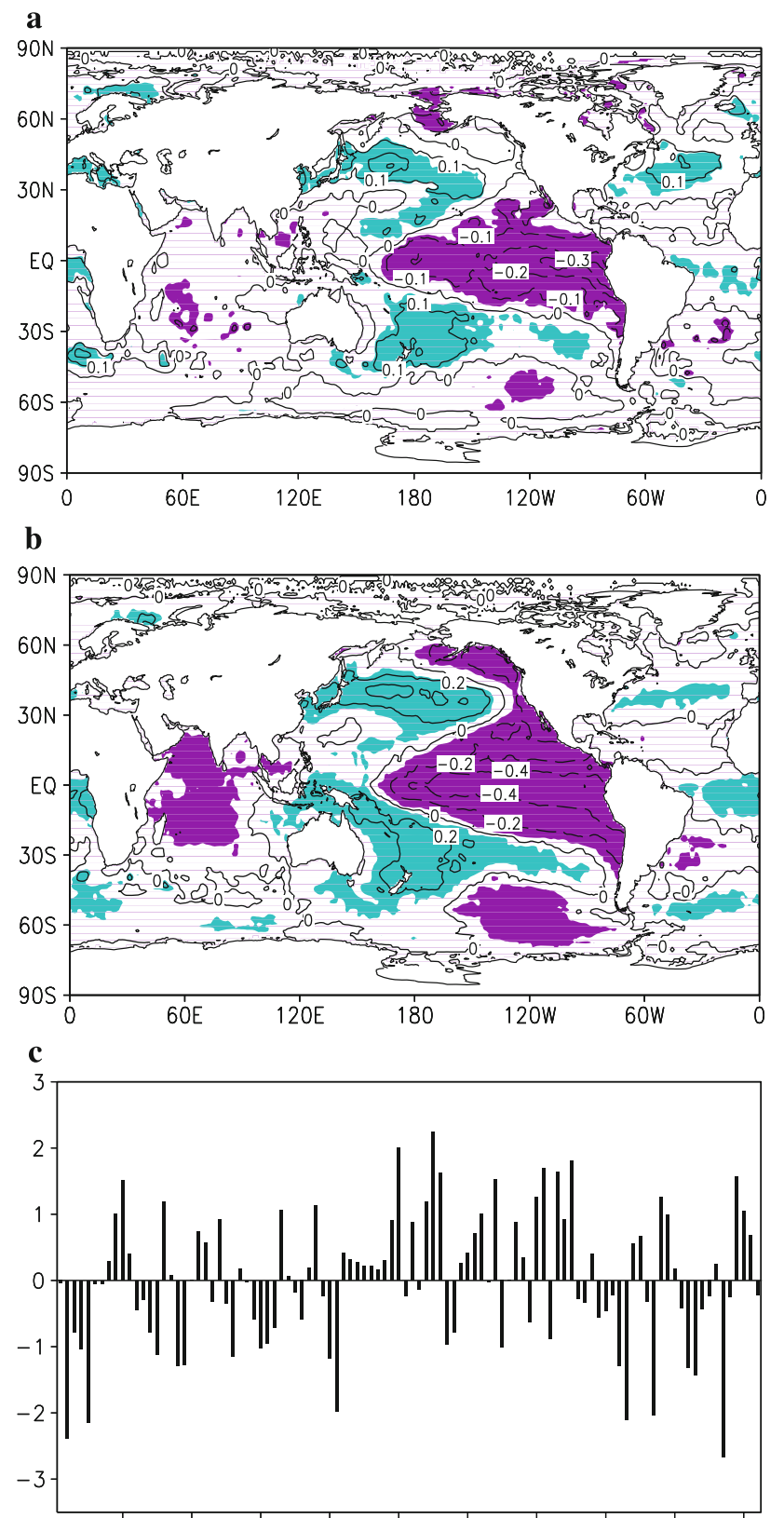

$191019201930 \quad 19401950 \quad 1960 \quad 1970 \quad 1980 \quad 1990 \quad 2000$

Fig. 7 a Regressed MJJAS SST $\left({ }^{\circ} \mathrm{C}\right)$ with reference to the APO index during 1901-2002 (shaded areas are significant at the $95 \%$ confidence); b EOF2 on the MJJAS SST anomaly during 1901-2002; and $\mathbf{c}$ the standardized time series of EOF2 shows that the EOF1 of SST, which accounts for $26 \%$ of the total variance, shows a consistent variation over the almost globe and its time series exhibited an increasing trend during 1901-2002 (figures not shown), which indicate a warming trend of the global SST. This increasing trend in SST is associated with global warming during the recent 100 years (Solomon et al. 2007). The EOF2 of SST (Fig. 7b), which accounts for $13 \%$ of the total variance, shows a pattern that resembles the APO-associated SST anomalies (shown in Fig. 7a), especially over the entire Pacific Ocean. On the interdecadal time scale, the time series of the SST EOF2 show an increasing trend before the late $1960 \mathrm{~s}$ and a general decreasing trend afterwards (Fig. 7c), reflecting a variation of the Interdecadal Pacific Oscillation (IPO) (e.g., Power et al. 1999; Mantua and Hare 2002). Meanwhile, the spectrum of the SST EOF2 also shows predominant peaks at 3-5 years (significant at the $95 \%$ level). The correlation analysis shows a positive correlation of 0.44 between the time series of the SST EOF2 and the APO index, significant at the $99.9 \%$ confidence level, which suggests a link between the APO and the global SST during boreal summer.

How do the SST anomalies associated with the MJJAS APO evolve on the annual time scale? Figure 8a shows the longitude-time cross section of the regressed monthly SST from last December to present December against the MJJAS APO index along $40^{\circ} \mathrm{N}$. It is evident that there is almost no large-scale significant anomaly of SST in the previous winter (December to February). The significant positive SST anomalies begin in late spring. Similarly, large-scale persistent negative (positive) SST anomalies over the equatorial central-eastern Pacific (the subtropical South Pacific) generally begin in May, without evident negative (positive) anomalies in the previous winter (Fig. 8b, c). Thus the Pacific SST anomalies associated with the boreal summer APO index do not originate from the previous winter and the summer climate anomalies associated with the variability of the APO may not be forced by the previous winter Pacific SST.

\section{Summary and discussion}

The boreal summer APO is a measure of the thermal contrast between Eurasia-northern Africa and North Pacific-North Atlantic. We have investigated the anomalies of the atmospheric circulation, the $\mathrm{NH}$ summer monsoon, and the global hydroclimate associated with the APO during the summer. When the APO index is high, the mid latitudes of Eurasia and northern Africa (the North Pacific, North America, and the North Atlantic) are warmer (colder) than normal throughout the troposphere, with a relatively cool troposphere over the tropical Indian Ocean. 
Fig. 8 a The longitude-time cross section of regressed monthly SST $\left({ }^{\circ} \mathrm{C}\right)$ from last December to present December with reference to the MJJAS APO index along $40^{\circ} \mathrm{N}$ during 1901-2002 [DEC0000

(JAN0001) in the $y$ coordinate indicates December (January) in the previous (current) year; shaded areas are significant at the $95 \%$ confidence]; and

(b) and (c) same (a) but along the equator and $30^{\circ} \mathrm{S}$, respectively

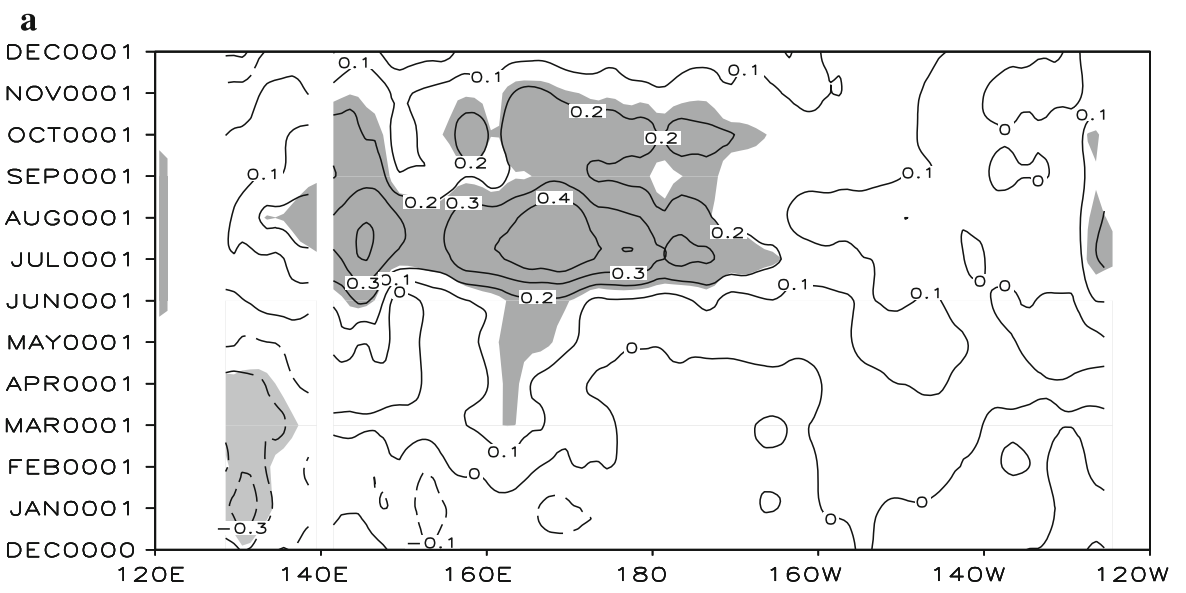

b

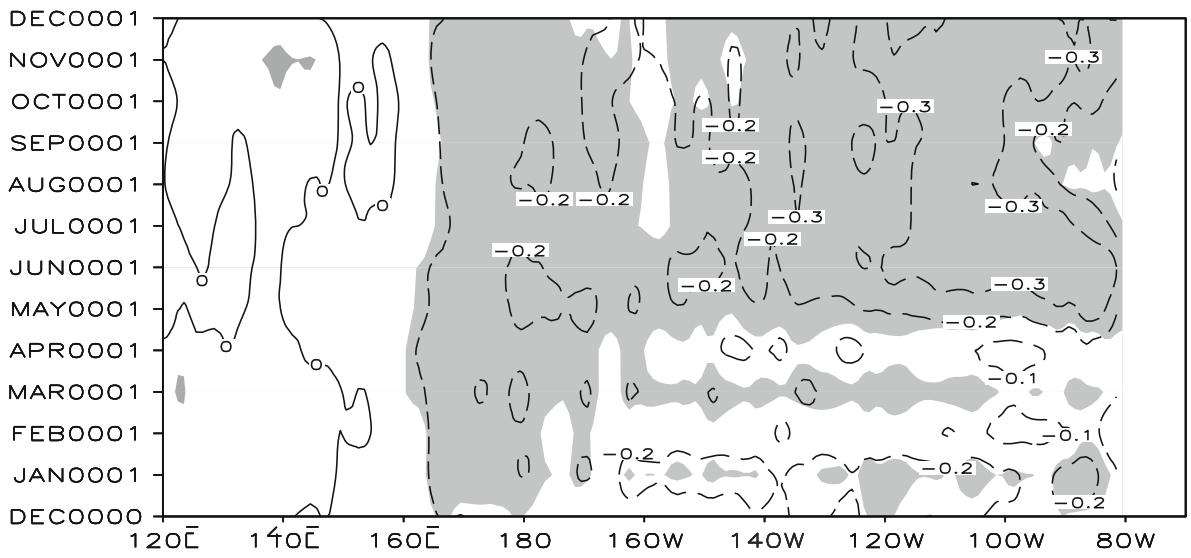

c

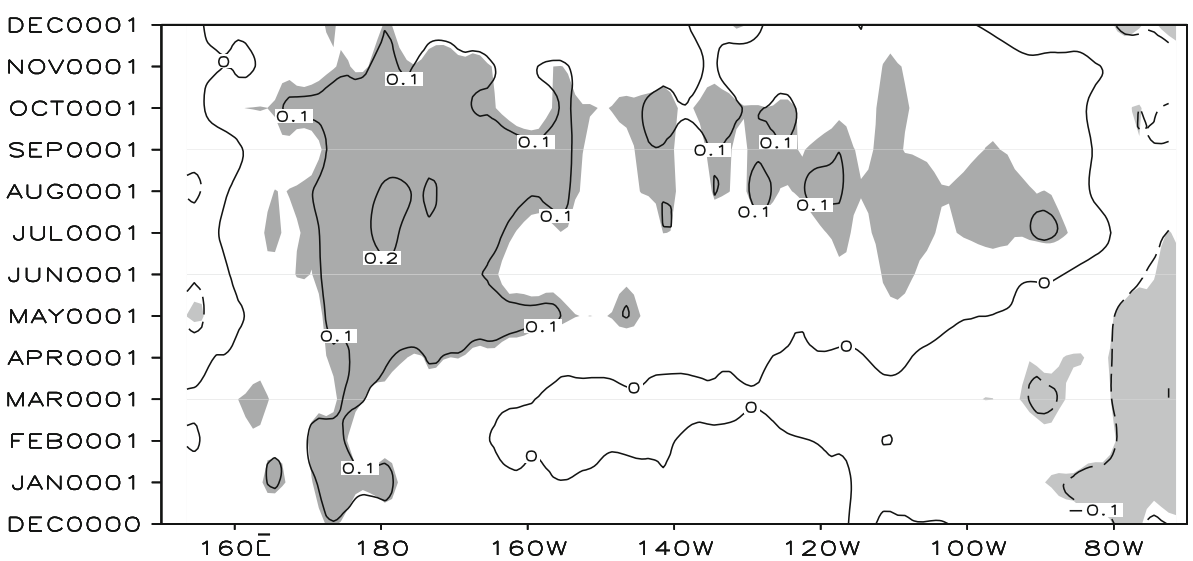

Thus the APO index reflects not only the zonal thermal contrast between Asia and the Pacific but also the meridional thermal contrast over South Asia. Corresponding to such temperature anomalies, in the upper troposphere, both the South Asian high and the troughs over the North Pacific and North Atlantic strengthens, while the Mexican ridge weakens. In the lower troposphere, there are enhanced continental lows over the Asian-African monsoon region and strengthened subtropical highs over the North Pacific and the North Atlantic. A weakened low occurs over the extratropics of North America. In the winter SH, low-level anomalous anticyclonic systems occur over the subtropics, with an upper-level anomalous anticyclonic system appears over the tropical South Indian Ocean and Australia and anomalous cyclonic circulation over the subtropical South Pacific.

The variability of the NHSM is significantly correlated with the APO anomaly. Corresponding to a high APO index, strengthened upper-level tropical easterly jet streams appear over the Asian-African monsoon region and 
enhanced low-level southerly or southwesterly winds blow from the South Indian Ocean into the Asian-African monsoon region, increasing the transportation of water vapor toward the monsoon region. The strengthened low-level convergence and upper-level divergence of air mass occur over the monsoon trough regions. These anomalous features generally increase summer monsoon precipitation, indicating a stronger Asian-African summer monsoon. In contrast, less summer precipitation appears over the arid and semiarid regions of northern Africa, the Middle East, and West Asia and over the extratropics of North America. This result also suggests an out-of-phase relationship in summer precipitation between the Asian monsoon region and the extratropics of North America. In the meantime, a wet-cold climate occurs over the African and South Asian tropical monsoon regions, which may contribute to an increase of soil moisture. A wet-hot climate generally occurs over the East Asian monsoon region and the increased precipitation is a major factor for an increase of the local soil moisture. A dry-hot climate occurs over the extratropics of North America, which decreases the local soil moisture. To assess the robustness of the above results obtained from analyzing the twentieth century reanalysis, we further analyze surface air temperature and precipitation anomalies associated with the APO index from the ERA-40 (NCEP) reanalysis datasets during 1958-2001 (1948-2002) and obtain the similar results (figures not shown), which further confirms the reliability of the twentieth century reanalysis.

A recent study of the global monsoon over the past millennium (Liu et al. 2012a) shows that the strength of the NHSM precipitation (over both the land and ocean) is determined by the $\mathrm{NH}\left(0^{\circ}-60^{\circ} \mathrm{N}\right)$ land-ocean thermal contrast (sea level pressure difference) and the thermal contrast between the NH and SH. Since the APO reflect the $\mathrm{NH}$ land-ocean thermal contrast, its reflection of the NHSM strength is consistent with Liu et al. (2012a).

Although the overall weakening trend of globally averaged land monsoon precipitation over the past five decades can generally be forced by ocean forcing, these simulations do not well capture such a trend in Asian monsoon regions that is important for the weakening trend of the global monsoon precipitation (Zhou et al. 2008a, b). In fact, the interdecadal variability of Asian monsoon over the past five decades is also modulated by Tibetan heating (Zhang et al. 2004; Zhao et al. 2010b). Thus, a comparative analysis of land and SST influences on multiple-time-scale variations of the NHSM may help to understand the mechanisms responsible for variability of the global monsoon precipitation.

The variability of APO during boreal summer is linked to variations in the Pacific and Atlantic SSTs. A high APO index corresponds to a cold tropical central-eastern Pacific and warm extratropical North and South Pacific Oceans and North Atlantic. Positive or negative SST anomalies over the Pacific mainly begin in late spring rather than the previous winter. This development of the tropical Pacific SST anomaly in spring supports the conclusion of Webster and Yang (1992). Their study showed that the winter condition of ENSO is strongly (weakly) correlated with the summer condition before (after) the winter. Thus such a poor correlation between the summer APO and the previous winter possibly implies a weaker influence of the previous winter Pacific SST on the boreal summer APO and associated climate anomalies. Moreover, some simulations also showed a weaker forcing of SST anomalies to the APO-like phenomenon (Zhou and Zhang 2009; Zhao et al. 2010a, 2011b). However, we do not understand the seasonal dependence of the SST-APO relationship. Further exploration on the physical implication of the APO-SST relationship deems necessary.

The previous studies have examined the relationships between the NH and $\mathrm{SH}$ from air mass redistribution (e.g., Guan and Yamagata 2001; Carrera and Gyakum 2003). Then, what mechanisms are responsible for the relationship of the APO with the SH atmospheric circulation and climate? More modeling studies may help understand this relationship, which will be addressed in the future work.

Acknowledgments We thank the NOAA Earth System Research Laboratory for providing the twentieth century reanalysis V2 data products, the Climatic Research Unit, University of East Anglia, United Kingdom for providing the surface air temperature and precipitation analysis data, the Hadley Centre, Met Office for providing the monthly mean HadISST data, Dr. A. Dai of NCAR for providing the monthly Palmer drought severity index, the Climate Diagnostic Center/NOAA for providing the NCEP-NCAR reanalysis, and the ECMWF for providing the ERA-40 reanalysis on their internets. This work was also sponsored by the National Key Basic Research Project of China (2009CB421404) and the National Natural Science Foundation of China (40921003). Bin Wang acknowledges support from NOAA Climate Test Bed project and the Global Research Laboratory (GRL) program, which is sponsored by the National Research Foundation of Korea (grant \# 2100-0021927).

Open Access This article is distributed under the terms of the Creative Commons Attribution License which permits any use, distribution, and reproduction in any medium, provided the original author(s) and the source are credited.

\section{References}

Carrera ML, Gyakum JR (2003) Significant events of interhemispheric atmospheric mass exchange: composite structure and evolution. J Climate 16:4061-4078

Chan JCL, Zhou W (2005) PDO, ENSO, and the early summer monsoon rainfall over south China. Geophys Res Lett 32:L08810. doi:10.1029/2004GL022015

Compo GP, Whitaker JS, Sardeshmukh PD (2006) Feasibility of a 100 -year reanalysis using only surface pressure data. Bull Am Meteor Soc 87:175-190 
Compo GP, Whitaker JS, Sardeshmukh PD, Matsui N, Allan RJ, Yin $\mathrm{X}$, Gleason BE, Vose RS, Rutledge G, Bessemoulin P, Brönnimann S, Brunet M, Crouthamel RI, Grant AN, Groisman PY, Jones PD, Kruk M, Kruger AC, Marshall GJ, Maugeri M, Mok HY, Nordli $\varnothing$, Ross TF, Trigo RM, Wang XL, Woodruff SD, Worley SJ (2011) The twentieth century reanalysis project. Q J Roy Meteorol Soc 137:1-28

Dai AG, Trenberth K, Qian TT (2004) A global dataset of Palmer drought severity index for 1870-2002: relationship with soil moisture and effects of surface warming. J Hydrometeorol 5:1117-1130

Fasullo J, Webster PJ (2002) Hydrological signatures relating the Asian summer monsoon and ENSO. J Climate 15:3082-3095

Guan ZY, Yamagata T (2001) Interhemispheric oscillations in the surface air pressure field. Geophys Res Lett 28:263-266

Hoskins BJ, Rodwell MJ (1995) A model of the Asian summer monsoon. Part I: the global scale. J Atmos Sci 52:1329-1340

$\mathrm{Hu}$ ZZ, Huang BH (2009) Interferential impact of ENSO and PDO on dry and wet conditions in the U.S. Great Plains. J Climate 22:6047-6065

Kalnay E et al (1996) The NCEP/NCAR 40-year reanalysis project. Bull Am Meteor Soc 77:437-471

Krishnan R, Sugi M (2003) Pacific decadal oscillation and variability of the Indian summer monsoon rainfall. Clim Dyn 21:233-242

Liu J, Wang B, Yim SY, Lee JY, Jhun JG, Ha KJ (2012a) What drives the global summer monsoon over the past millennium? Clim Dyn. doi:10.1007/s00382-012-1360-x

Liu G, Zhao P, Wu R, Chen J (2012b) Potential flaws of interdecadal changes over eastern China around the early 1990s in the National Centers for Environmental Prediction-National Center for Atmospheric Research reanalyses, J Geophys Res 117(D02111). doi:10.1029/2011JD016327

Mantua NJ, Hare SR (2002) The Pacific decadal oscillation. J Oceanogr 58:35-44

McCabe GJ, Palecki MA, Betancourt JL (2004) Pacific and Atlantic Ocean influences on multidecadal drought frequency in the United States. Proc Natl Acad Sci USA 101:4136-4141

New M, Hulme M, Jones P (2000) Representing twentieth century space-time climate variability. Part I: Development of a 1901-96 monthly grids of terrestrial surface climate. J Climate 13:2217-2238

Power S, Casey T, Folland CK, Colman A, Mehta V (1999) Interdecadal modulation of the impact of ENSO on Australia. Clim Dyn 15:319-323

Rayner NA, Parker DE, Horton EB, Folland CK, Alexander LV, Rowell DP, Kent EC, Kaplan A (2003) A Global analyses of sea surface temperature, sea ice, and night marine air temperature since the late nineteenth century. J Geophys Res 108 (D14): 4407. doi:10.1029/2002JD002670

Ropelewski CF, Halpert MS (1987) Global and regional scale precipitation patterns associated with the El Niño/Southern Oscillation. Mon Wea Rev 115:1606-1626

Solomon S, Qin D, Manning M, Marquis M, Averyt K, Tignor MMB, Miller HL Jr, Chen Z (eds) (2007) Climate change 2007: The physical science basis. Cambridge University Press, Cambridge

Sun Y, Ding YH, Dai A (2010) Changing links between South Asian summer monsoon circulation and tropospheric land-sea thermal contrasts under a warming scenario. Geophys Res Lett 37:L02704. doi:10.1029/2009GL041662

Uppala SM, Kallberg PW, Simmons AJ et al (2005) The ERA-40 reanalysis. Q J R Meteorol Soc 131:2961-3012. doi:10.1256/ qj.04.176

Wang B, Ding Q (2006) Changes in global monsoon precipitation over the past 56 years. Geophys Res Lett 33:L06711. doi: 10.1029/2005GL025347
Wang B, Ding Q (2008) Global monsoon: Dominant mode of annual variation in the tropics. Dyn Atmos Oceans 44:165-183

Wang B, Wu RG, Fu XH (2000) Pacific-East Asian teleconnection: how does ENSO affect East Asian climate? J Climate 13:1517-1536

Wang B, Wu RG, Lau KM (2001) Interannual variability of the Asian summer monsoon: contrasts between the Indian and the western North Pacific-east Asian monsoons. J Climate 14:4073-4090

Wang B, Liu J, Kim HJ, Webster PJ, and Yim SY (2012) Recent Change of the global monsoon precipitation (1979-2008), Clim Dyn. doi:10.1007/s00382-011-1266-z

Webster PJ, Yang S (1992) Monsoon and ENSO: Selectively interactive systems. Q J Roy Meteor Soc 118:877-926

Webster PJ, Magaña VO, Palmer TN, Shukla J, Tomas RA, Yanai M, Yasunari T (1998) Monsoons: processes, predictability and the prospects for prediction. J Geophys Res 103:14 451-14 510

Yang S, Lau KM (1998) Influences of sea surface temperature and ground wetness on Asian summer monsoon. J Climate 11:3230-3246

Yoon J, Yeh S (2010) Influence of the Pacific Decadal Oscillation on the relationship between El Niño and the Northeast Asian summer monsoon. J Climate 23:4525-4537

Yu R, Zhou T (2007) Seasonality and three-dimensional structure of interdecadal changes in the East Asian monsoon. J Climate 20:5344-5355

Yu R, Wang B, Zhou T (2004) Tropospheric cooling and summer monsoon weakening trend over East Asia. Geophys Res Lett 31:L22212. doi:10.1029/2004GL021270

Zhang L, Zhou T (2011) An assessment of monsoon precipitation changes during 1901-2001. Clim Dyn 37:279-296

Zhang Y, Li T, Wang B (2004) Decadal change of the spring snow depth over the Tibetan Plateau: The associated circulation and influence on the East Asian summer monsoon. J Climate 17:2780-2793

Zhao P, Zhu YN, Zhang RH (2007) An Asian-Pacific teleconnection in summer tropospheric temperature and associated Asian climate variability. Clim Dyn 29:293-303

Zhao P, Cao ZH, Chen JM (2010a) A summer teleconnection pattern over the extratropical Northern Hemisphere and associated mechanisms. Clim Dyn 35:523-534

Zhao P, Yang S, Yu R (2010b) Long-term changes in rainfall over Eastern China and large-scale atmospheric circulation associated with recent global warming. J Climate 23:1544-1562

Zhao P, Yang S, Wang HJ, Zhang Q (2011a) Interdecadal relationships between the Asian-Pacific Oscillation and summer climate anomalies over Asia, North Pacific and North America during a recent 100 Years. J Climate 24:4793-4799

Zhao P, Yang S, Jian MQ, Chen JM (2011b) Relative controls of Asian-Pacific summer climate by Asian land and tropical-North Pacific sea surface temperature. J Climate 24:4165-4188

Zhou T, Zhang J (2009) Harmonious inter-decadal changes of JulyAugust upper tropospheric temperature across the North Atlantic, Eurasian continent, and North Pacific. Adv Atmos Sci 26:656-665

Zhou T, Zhang L, Li H (2008a) Changes in global land monsoon area and total rainfall accumulation over the last half century. Geophys Res Lett 35:L16707. doi:10.1029/2008GL034881

Zhou T, Yu RC, Li HM, Wang B (2008b) Ocean forcing to changes in global monsoon precipitation over the recent half-Century. J Climate 21:3833-3852

Zhu YM, Yang XQ (2003) Relationships between Pacific Decadal Oscillation (PDO) and climate variabilities in China. Acta Meteor Sin 61:642-654 (in Chinese) 